\title{
A humanidade às avessas em "A terra dos meninos pelados" de Graciliano Ramos
}

\author{
Humanity to the adverses in Graciliano Ramos's "The land of naked boys" \\ Maria Souza da Rocha*, Suiane Cabral Magalhães \\ Como citar esse artigo. ROCHA, M.S.; \\ MAGALHÃES, S.C. A humanidade

\section{Resumo} às avessas em "A terra dos meninos pelados" de Graciliano Ramos. Revista Mosaico, v.12, n.1, p. 60-67, 2021

A humanidade, na visão de alguns estudiosos, vive uma crise de identidade com a recente globalização com repercussões no pensamento e nas atitudes, exigindo uma reflexão no enfrentamento dos desafios da atualidade. Surgindo, dessa forma, uma nova ordem social que altera valores, e faz emergir novas sociabilidades. $\mathrm{O}$ velho mundo em transformação com a emergência de novos paradigmas que o entenda, que o explique. Este artigo propõe algumas reflexões, sobre os desafios no enfrentamento de aceitação das diferenças da humanidade na contemporaneidade e tem como objetivo analisar a obra do autor Graciliano Ramos, "A terra dos meninos pelados", evidenciando a trajetória do protagonista Raimundo, menino sonhador, protagonista do conto, que enfrenta discriminação e cria um mundo fantástico, terra de Tatipirun, como forma de reconstrução da sua realidade. Para ir a fundo com essas reflexões procurou-se abordar alguns autores engajados nessa causa como Boaventura de Souza Santos $(2007 ; 2010)$, que escreve sobre as sociologias e as epistemologias do Sul, discute ainda sobre o pensamento abissal, afirmando que assim como a cultura, as epistemologias foram suprimidas com o processo de colonização. Ao lado deste citaremos ainda Mikhail Bakhtin (1929) com o estudo da consciência individual como um fator sócio ideológico e, por fim, Edgar Morin (2003) trazendo a reforma do pensamento para um ensino que vá além do transmitir um mero saber, mas produza uma cultura que nos permita compreender nossa condição de seres compostos de humanidades. A metodologia deste trabalho é qualitativa e utiliza-se a pesquisa bibliográfica.

Palavras-chave: Humanidade. Diferenças. Emancipação social.

\begin{abstract}
Humanity, in the view of some scholars, is experiencing an identity crisis with the recent globalization and its repercussions on thinking and attitudes, requiring reflection in facing the challenges of today. In this way, a new social order emerges that alters values, giving rise to new sociability. The old world in transformation with the emergence of new paradigms that understand it, that explain it. This article proposes some reflections on the challenges in facing the acceptance of the differences of humanity in contemporary times and aims to analyze the work of the author Graciliano Ramos, "The land of naked boys", showing the trajectory of the protagonist Raimundo, a dreamy boy, protagonist of the short story, which faces discrimination and creates a fantastic world, the land of Tatipirun, as a way of reconstructing its reality. To go deeper with these reflections, we tried to approach some authors engaged in this cause, such as Boaventura de Souza Santos $(2007 ; 2010)$, who writes about sociologies and epistemologies of the South, also discusses abyssal thinking, stating that as well as culture, epistemologies were suppressed with the colonization process. Next to this we will also mention Mikhail Bakhtin (1929) with the study of individual conscience as a socio-ideological factor and, finally, Edgar Morin (2003) bringing the reform of thought to a teaching that goes beyond transmitting a mere knowledge, but produces a culture that allows us to understand our condition as beings composed of humanities. The methodology of this work is qualitative and bibliographic research is used.

Keywords: AHumanity. Differences. Social emancipation.
\end{abstract}

\section{1 - Introdução}

Neste artigo apresentaremos uma análise do conto A terra dos meninos pelados (1939), de Graciliano Ramos, que conta a trajetória de Raimundo, menino sonhador, protagonista do conto, em uma viagem à terra de Tatipirun, mundo fantástico criado pelo o autor, onde o personagem foge da discriminação sofrida. $\mathrm{O}$ objetivo é refletir sobre as construções e reconstruções da realidade dentro de uma modernidade líquida, em que os valores são fluidos, mas a integração social enfraquecida.
$\mathrm{O}$ autor da obra $A$ terra dos meninos pelados, Graciliano Ramos de Oliveira nasceu em 27 de outubro de 1892, na cidade de Quebrângulo, Alagoas. Ramos é um dos maiores literatos brasileiro, e também foi prefeito da cidade de Palmeiras dos Índios. Com este trabalho ele veio inovar a literatura infanto-juvenil fazendo dentro da obra o uso de uma linguagem coloquial, usando o universo imaginário para demonstrar a realidade das diferenças que constrói as interações da pessoa humana. A obra foi concluída no final dos anos 30 , juntamente com outras obras peculiares do autor, como as histórias de "Alexandre e outros heróis" e "Pequena História da República". Neste período Graciliano Ramos recebeu o Ađiliação dos autores: 
Prêmio de Literatura Infantil, concedido pelo Ministério da Educação. ${ }^{1}$

O livro A terra dos meninos pelados, de Graciliano Ramos é uma grande metáfora da alma humana. A obra tem como protagonista, Raimundo, o menino que tinha o olho direito preto, o esquerdo azul e a cabeça era pelada. Por isso os meninos de sua rua zombavam dele, o qual sempre entristecia e o seu rosto ficava escuro. Ele passa então, por um conflito interior gerado por causas exteriores de discriminação. Fazendo uma "viagem" chega ao centro da própria existência. Nessa viagem Raimundo encontra em Tatipirun um grupo de crianças iguais a ele. Cada um com sua diferença, com sua dificuldade, que ao olhar alheio thes faziam incapazes, mas juntos, cada um na sua diferença ou na sua igualdade, formavam uma comunidade única em sua grandeza.

A obra é dividida em 23 capítulos bem narrados. Tatipirun é uma cidade em que todos são iguais a Raimundo, o protagonista. Todos têm os olhos de duas cores e a cabeça pelada, e os seres inanimados são reais. Falam, dialogam e riem. Graciliano faz o uso de neologismos e seus personagens têm nomes bem diferentes: Caralâmpia, Pirenco, Talima, Sira e Pirundo, que os tornam mais iguais. Ramos, usa o próprio nome do protagonista para mostrar a igualdade e a importância da repetição do simples e do comum, escolhendo o nome: Raimundo, como protagonista principal.

Analisando a obra de Ramos compreendemos como a construção da subjetividade vai muito além da vinculação ao espaço físico, logo, a objetividade/ realidade física por si só não pode expressar a identidade dos seres, das humanidades. Mas esse espaço físico e social também pode ser um universo de exclusões, como o que vivenciamos no mundo contemporâneo repleto de "Raimundos", perdidos nas avessas da realidade social de um universo globalizado ${ }^{2}$, que contraditoriamente une, mas que cada vez mais se mostra indiferente às diferenças individuais e sociais.

Aspectos físicos não podem ser a razão principal para se conhecer o indivíduo. O conhecimento deveria ser mais subjetivo. Além disso, a objetividade/realidade física por si só não pode expressar a identidade dos seres, das humanidades. Edgar Morin (2003), sinaliza a necessidade de um conviver consciente em relação ao universo e ao outro, pois somos seres, simultaneamente, cósmicos, físicos, biológicos, culturais, cerebrais, espirituais e sociais. Para desenvolver estes objetivos, optou-se pelas reflexões realizadas também por Boaventura de Souza Santos $(2007 ; 2010)$ e Mikhail Bakhtin (1929), que abordam discussões sobre as intersubjetividades, as relações sociais e seus desdobramentos, dentro de contextos complexos de inclusão e exclusão das múltiplas realidades e saberes.

Por fim, para a elaboração deste trabalho foi dado enfoque qualitativo, sendo utilizada a pesquisa bibliográfica, utilizando obras dos autores citados acima, tendo como livro principal de análise do texto $A$ terra dos meninos Pelados, de Graciliano Ramos.

\section{Aporte Teórico}

\section{Sociologia Da Vida Cotidiana}

Graciliano Ramos em sua obra $A$ terra dos meninos pelados, cria um mundo imaginário, onde ele retrocede a um "mundo paraíso", de conhecimentos não alienados, de uma despreocupação aquém, fortalecendo a relação homem e natureza. As contradições faze-o andar sempre para frente, o mesmo expõe: “- Pois eu acho que está chegando a hora de voltar e descansar. Voltar para onde? - Voltar para a beira do rio, entrar em casa, dormir. - Não vale a pena. Se quer ver o rio, é tocar para a frente" (RAMOS, 1939, p.14). Essas contradições entram em uma ligação de exterioridade com a vida cotidiana, pois em meio a complexidade da vida e trajetória biográficas, os sujeitos constroem sentidos múltiplos a partir do senso comum, para Martins (1998, p.3-4),

\footnotetext{
O senso comum é comum não porque seja banal ou mero e exterior conhecimento. Mas porque é conhecimento compartilhado entre os sujeitos da relação social. Nela o significado a precede, pois é condição de seu estabelecimento e ocorrência. Sem significado compartilhado não há interação. Além disso, não há possibilidade de que os participantes da interação se imponham significados, já que o significado é reciprocamente experimentado pelos sujeitos. A significação da ação é, de certo modo, negociada por eles. Em princípio, não há um significado prévio ou, melhor dizendo, não é necessário que haja significações preestabelecidas para que a interação se dê. (MARTINS, 1998, p. 3-4)
}

As múltiplas possibilidades de interação possibilitam a construção do senso comum, sentido compartilhado pelos sujeitos, podendo também ser agregado novos significados ao longo do tempo. Em segundos, nossa imaginação simula significados antes de interagirmos com o outro, numa relação de exterioridade consigo mesmo.

O âmbito das interações sociais se ampliam em uma sociedade globalizada, e também fluida (BAUMAN, 2001) em razão das mudanças de valores, pensamentos e formas de ser. Com a sociedade a todo momento sendo reinventada, os sujeitos precisam se readaptar a um novo universo de sentido, a um novo viver, e isso é abordado claramente por Graciliano através das mudanças de mundo que seu protagonista faz constantemente.

Compreende-se, que a realidade do dia a dia muda as circunstâncias da nossa história fazendo com que frequentemente estejamos nos adaptando ao novo 
e reinventando-se a partir de nossas vivências, "o reino do cotidiano é o reino em que a necessidade se coloca como uma experiência concreta, seja pela escassez, seja por sua satisfação imediata." (LACOMBE, 2008 p.153). Este universo de escassez e satisfação do presente agrega inquietações e contradições, marcada por uma tenebrosa sensação de sobrevivência (BHABHA, 1949), que culminam em novas possibilidades de criação de sentido e reflexão.

Em A terra dos meninos pelados de Graciliano Ramos, o personagem principal, Raimundo, evidencia novas possibilidades de criação e reflexão, a partir da mudança de lugar, de sentido, de relações sociais, que acontece quando o protagonista passa de um lugar de exclusão, em que os vizinhos o consideravam estranho e zombavam dele, para um outro espaço em que as pessoas não o viam como diferente, mas o tratavam como semelhante:

Havia um menino diferente dos outros meninos. Tinha o olho direito preto, o esquerdo azul e a cabeça pelada. Os vizinhos mangavam dele e gritavam: —Ó pelado!

Tanto gritaram que ele se acostumou, achou o apelido certo, deu para se assinar a carvão, nas paredes: Dr. Raimundo Pelado [...]. Não tendo com quem entender-se, Raimundo Pelado falava só, e os outros pensavam que ele estava malucando. Estavanada! Conversavasozinhoedesenhavanacalçadacoisas maravilhosas do país de Tatipirun, onde não há cabelos e as pessoas têm um olho preto e outro azul. (RAMOS, 1939, p. 5).

Viver em dois mundos de sentido opostos revela as complexidades de Raimundo como ser no mundo, mas também o desafio da mudança de concepções, de realidades e de mundos diferentes. A questão que se coloca é se seria possível a integração desses dois universos em um cotidiano que se perfaz contraditório, irregular e complexo? Em um espaço em que as visões de mundo se constroem de formas distintas . Para Edgar Morin (2003, p. 9), deve-se buscar a construção de uma cultura unificada, "permitindo ao homem compreender sua condição no cosmo, favorecendo, um modo de pensar aberto e livre" como é perceptível no país de Tatipirun, vivido por Raimundo Pelado.

Esse caminho requer "[...] um tipo de inteligência que precisa ser reformada", assevera Morin (2003, p. 20). Essa nova inteligência é perceptível no personagem Raimundo, que é capaz de perceber o contexto e o complexo, uma vez que ele pode associar informações de seus dois mundos, integrando-as com o mundo real e o imaginário, construindo novos sentidos.

A inteligência a partir do prisma da complexidade agrega e não exclui, porque reconhece as irregularidades e contradições das relações sociais ${ }^{4}$. Passa-se a pensar não apenas em um nível de realidade, mas em múltiplos níveis que integram diferentes leituras de mundo (FREIRE, 1992). Logo, evidenciando significados distintos que os indivíduos e grupos dão para a sua existência.

Quando não existe a compreensão das múltiplas leituras de mundo em um espaço marcado por contradições e complexidades, por vezes o que ocorre é a exclusão de determinados indivíduos ou grupos que não se encaixam em uma visão de mundo. $\mathrm{O}$ que se observa na vida do personagem Raimundo é que no seu "mundo real" as pessoas que o cercam não o valorizam, como é evidente na citação abaixo

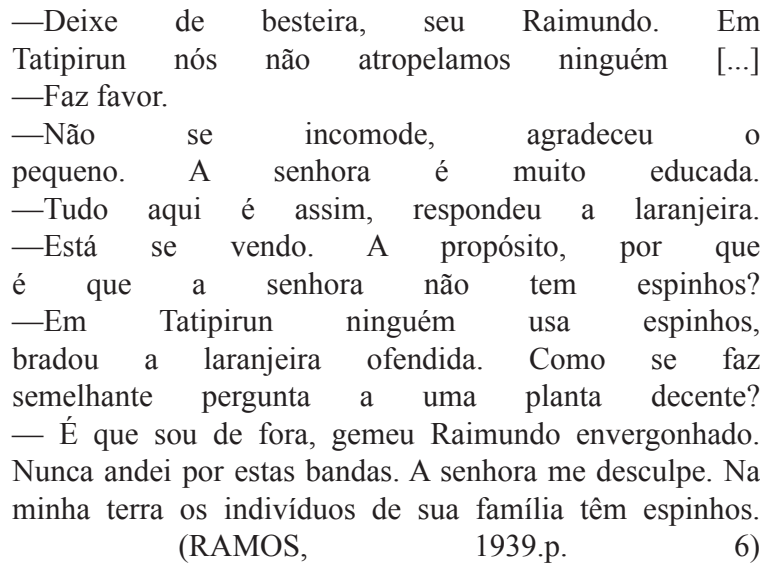

O trecho pode evidenciar a dificuldade de se integrar múltiplas visões de mundo, de ser e existir. Provavelmente por esse motivo o menino pelado viaja a outro mundo em busca de aceitação, mais que isso, em busca de uma reforma do pensamento, em que todas as concepções possam ser aceitas, as diferenças são respeitadas. Para uma reforma no pensamento Morin (2003, p. 104) propõe que:

\begin{abstract}
A reforma de pensamento é uma necessidade histórica fundamental. Hoje somos vítimas de dois tipos de pensamento fechado: primeiro, o pensamento fracionário da tecnociência burocratizada, que corta, como fatias de salame, o complexo tecido do real; segundo, o pensamento cada vez mais fechado, voltado para a etnia ou a nação, que recorta, como um puzzle, o tecido da Terra-Pátria. Precisamos, pois, estar intelectualmente rearmados... Essa é uma reforma vital para os cidadãos do novo milênio.
\end{abstract}

Necessita-se de uma reformulação de paradigmas, onde a educação deve desenvolver a capacidade de transformar conhecimento em sabedoria e a informação que recebemos em experiência de vida. Ou seja, um renascimento da humanidade de repensar seus problemas nesta era planetária, onde vive-se um progresso econômico e um desenvolvimento das comunicações, interligando o mundo em tudo.

A reforma do pensamento, poderá servir como um caminho de integração de realidades distintas. Para Morin (2003), há uma necessidade de um pensamento que compreenda que o conhecimento das partes depende do conhecimento do todo e que o conhecimento do todo depende do conhecimento das partes. Que seja reconhecido e examinado os fenômenos 
multidimensionais, tratando as realidades, de formas solidárias e conflituosas respeitando a diferença e reconhecendo a unicidade.

Os problemas basilares da sociedade não devem ser fragmentados pois envolvem a globalidade, a complexidade e a expansão do saber na conjuntura do planeta. Morin traz em sua discussão o desafio cultural que tem por finalidade remediar a separação entre a cultura das humanidades e a cultura científica (que influencia uma forma racionalizada de pensar) de maneira a humanizar o saber. Para o autor,

A cultura, daqui em diante, está não só recortada em peças destacadas, como também partida em dois blocos. A grande separação entre a cultura das humanidades e a cultura científica, iniciada no século passado e agravada neste século XX, desencadeia sérias consequências para ambas. A cultura humanística é uma cultura genérica, que, pela via da filosofia, do ensaio, do romance, alimenta a inteligência geral, enfrenta as grandes interrogações humanas, estimula a reflexão sobre o saber e favorece a integração pessoal dos conhecimentos. A cultura científica, bem diferente por natureza, separa as áreas do conhecimento; acarreta admiráveis descobertas, teorias geniais, mas não uma reflexão sobre o destino humano e sobre o futuro da própria ciência. A cultura das humanidades tende a se tornar um moinho despossuído do grão das conquistas científicas sobre o mundo e sobre a vida. (Morin, 2003, p. 17-8).

Essas questões permitem simultaneamente procedimentos de ligação e de separação, articulando diferentes saberes. No entanto, falta uma reorganização no que diz respeito ao humano, falta uma junção entre ciências humanas e ciências da vida, falta o reconhecimento de todas as raças e de todos os saberes, falta compreender que a ciência, que influencia em uma forma de pensar racionalizada, tem sua complementariedade, ou seja, pode integrar os saberes tradicionais, com um olhar mais atento voltado para a humanização.

É através da complexidade do cotidiano de Raimundo que percebemos esses procedimentos de ligação e de separação na própria vida do personagem principal, em A Terra dos meninos pelados, quando ele vive uma realidade que o separa, devido sua diferença, e quando ele está no outro mundo em que ele é visto como um igual. Assim, é notório uma relação de uma existência e outra nos levando a refletir acerca das relações humanas com o diferente e com o incomum, em um universo de sentidos múltiplos, que tentam diariamente se conectar uns aos outros. Essa conexão de sentidos não é um processo fácil, como percebida na obra e nas discussões realizadas pelos autores MORIN (2003), SANTOS (2008) e FREIRE (1992), mas que existe um caminho possível de interligação entre diferentes visões de mundo, que pode se concretizar com a reforma de nosso pensamento racional para um pensamento complexo.

\section{Caralâmpia, Pirenco, Talima, Sira E Pirundo - A Dimensão Ideológica Do Léxico}

A interação por meio da linguagem se dá num contexto em que todos participam em condição de igualdade. Em A terra dos meninos pelados, Raimundo, protagonista da narrativa consegue realizar a interação, que anteriormente não havia em seus momentos silenciosos durante os quais apenas ouvia os insultos que lhe faziam. Quando ele decide transpor a obscuridade daqueles momentos de seu cotidiano, ele passa a adentrar o "mundo fantasioso" de seus desejos. Quando encontra seus novos amigos, ele espanta-se com os seus nomes - Caralâmpia, Pirenco, Talima e Sira, pois encontra estrangeirismos nos nomes dos cidadãos daquela terra. Ideologicamente, cada nome representando a diferença de cada um. O léxico se refletindo e refratando no exterior, remetendo-se a algo situado fora de si mesmo.

O protagonista Raimundo ao criar neste "mundo imaginário" nomes diferentes para seus amigos e fora da normalidade do léxico de seu "mundo real" tenta fugir de uma padronização imposta e busca dar vida a um espaço democrático, quando viaja dentro de uma nova cultura. Ao ignorar os atos da natureza, como dia e noite, o protagonista ainda procurar fugir das regras que lhe afligiam e da preocupação com o tempo. Ele precisava dessa liberdade de "monitorar" o tempo segundo suas ânsias, fugindo assim de suas incertezas na interação com outros sujeitos.

Nesse contexto, o ser humano em sua complexidade busca compreender as suas incertezas, pois "a compreensão humana nos chega quando sentimos e concebemos os humanos como sujeitos; ela nos torna aberto a seus sofrimentos e suas alegrias" (MORIN, 2003, p.51). Entender essa complexidade exige uma Interseccionalidade ${ }^{5}$ entre todas as formas de conhecimentos, uma epistemologia reflexiva de auto entendimento. Um reajuste de conhecimento e sabedoria, interligadas pela linguagem.

Para Santos,

A 'ciência' (conhecimento e sabedoria) não pode ser separada da linguagem; A língua não são apenas fenômenos 'culturais' em que pessoas encontram a usa 'identidade'; elas também são o lugar onde se inscreve o conhecimento. E, dado que as línguas não são algo, que os seres humanos têm, mas algo de que os seres humanos são, a colonialidade do poder e a colonialidade do conhecimento engendraram a colonialidade do ser(MIGNOLO, 2003,p. 633 apud SANTOS, 2010,p.356)

O trecho nos faz refletir acerca do conhecimento e da sabedoria por meio da ciência, uma vez que as línguas além de serem fenômenos culturais também são o lugar em que o conhecimento está inserido, entendese que a língua faz parte do indivíduo como parte do 
seu ser. Isso mostra também que o ser humano é um ser complexo, biológico e também cultural.

Nessa conjuntura, Bakhtin (2006) enxerga a linguagem como um constante processo de interação mediado pelo diálogo - e não apenas como um sistema autônomo. A língua materna, seu vocabulário e sua estrutura gramatical, não conhecemos por meio de dicionários ou manuais de gramática, mas graças aos enunciados concretos que ouvimos e reproduzimos na comunicação efetiva com as pessoas que nos rodeiam. "Tudo que é ideológico possui um significado e remete a algo situado fora de si mesmo [...] sem signos, não existe ideologia" (BAKHTIN, 1929, p. 29).

Quando Freire (1992) escreveu Pedagogia da Esperança, ele quis mostrar que a educação democrática se dá a partir de uma linguagem que suscite um caminho para a invenção de uma cidadania. Segundo Freire (1992, p. 36) "Mudar a linguagem faz parte do processo de mudar o mundo" Assim, quando Raimundo percebe uma nova linguagem e suas significações naquele novo mundo, ele entende as possibilidades de um espaço/ambiente mais ético, mais compreensivo, e principalmente mais humano. Isso nos direciona a uma compreensão de que a linguagem, através da literatura, nos possibilita uma esfera de reflexão sobre as relações humanas em sua dimensão não apenas social e cultural, mas existencial.

\section{O Mundo Maravilhoso De "Santos" Na Terra Dos Meninos Pelados De "Ramos"}

A reinvenção da emancipação socialé uma questão de análise de Boaventura de Souza Santos. O escritor suscita possibilidades de como resolver as mazelas e trazer uma transformação real para a construção de uma sociedade mais interativa e consensual entre os seus. Ele traz os saberes culturais, a diversidade de ideias fora do tecnicismo como possíveis capacidades de uma sociedade mais humana. Tudo depende dos grupos que formam essa sociedade. Trata-se, portanto, de uma análise fundamental para entender a emancipação social na sociedade moderna.

"As promessas da modernidade - a liberdade, a igualdade e a solidariedade - continuam sendo uma aspiração para a população mundial". (SANTOS, 2007, p. 19). Nesse contexto, as teorias das ciências sociais que poderiam nos trazer essas maravilhas, estão fora de lugar. Não se ajustam a nossas realidades sociais. Boaventura Santos contextualiza:

[...] vivemos um problema complicado, uma discrepância entre teoria e prática social, que é nociva para a teoria e também para a prática. Para uma teoria veja a prática social é invisível; para uma prática cega, a teoria social é irrelevante[...] necessitamos é de um novo modo de produção de conhecimento. Não necessitamos de alternativas, necessitamos é de um pensamento alternativo às alternativas. (SANTOS, 2007, p. 19)

É necessário, uma reflexão epistemológica para que entendamos um conhecimento tão global como a globalização (SANTOS, 2007, p.21). De certa forma, a globalizaçãoveioporumadominação capitalista, colonial e patriarcal. Tornando-se dominações epistemológicas, gerando uma relação bastante iníqua entre saberes, fazendo com que os saberes peculiares dos povos e nações colonizados, bem como diversas outras formas de saber fossem suprimidos e inferiorizados. Dessa forma, algumas experiências sociais são desperdiçadas por ocorrerem em comunidades inferiorizadas, e não terem a visibilidade e sim uma neutralidade, ofuscando algumas realidades.

Em A terra dos meninos pelados, Raimundo cria em seu mundo imaginário uma relação de fuga à cultura imposta e encoraja-se para ir além. Elevar-se metaforicamente e encarar as mudanças para encontrar um mundo inteiramente maravilhoso, capaz de se moldar para seu conforto físico e moral: rios que se fecham para ele passar, caminhos sempre certos. Integrando-se gradativamente à nova terra, ele vai conhecendo todos os seus habitantes, crianças como ele, que jamais se tornarão adultas, pois o tempo em Tatipirun não passa.

Percebe-se que, no mundo real onde vive Raimundo, predomina a segregação e o desprezo por sua condição de ser diferente: olhos de cor diferente, cabeça pelada e personalidade que vive a devanear. A personagem cria um novo lugar, um utópico lugar onde pode ter sua individualidade respeitada. Seria um processo de desconstrução de um mundo de imagens discriminatórias para uma nova realidade.

SANTOS (2007) busca uma emancipação social, para alcançar respostas as nossas inquietações e aspirações, querendo atingir uma sociedade mais justa e inclusiva. Entendendo que,

a capacidade de síntese densa, engendrando crítica e anúncio, somente pode resultar de autores abertos ao debate crítico e com compromisso ético-político com as lutas de movimentos e organizações sociais e políticas, que apostam não apenas na emancipação política, mas, sobretudo, na emancipação humana e social. (SANTOS, 2007, p. 7)

Retornando ao conto A terra dos meninos pelados, observa-se que Raimundo foge da realidade que o discrimina. Escritor e personagem analisados em tipologias textuais diferentes, em uma temporalidade distante buscam o mesmo intento - a faculdade de libertarse das imagens primeiras, de buscar a desconstrução de uma realidade de imagens opressoras para a criação de um conjunto de imagens benéficas a suas próprias realidades.

Boaventura (2007) inquieta-nos com a grande dificuldade de pensar o novo. De acordo com o autor, 
"muitas vezes precisamos migrar de um campo a outro, de um estrato a outro, de uma linguagem a outra, de uma ciência a outra." (2007, p. 49). Às vezes o novo está em nosso conjunto de sociabilidades, por isso pensar o novo requer "encarar" uma complexidade de articulações. Ramos (1939), trouxe na obra A terra dos meninos pelados, o novo como possibilidade de "esconder", esquecer as contrariedades do real, na tentativa de se construir outro lugar, outro cotidiano, outro espaço de sociabilidade como possibilidade de união do homem e do cotidiano.

\section{O Homem "Entre" O Paradoxo Do Lugar e o Cotidiano}

O homem hoje tem uma nova relação com o mundo, marcada por construções e desconstruções de valores, uma vez que as relações fluidas estão propensas a mudar a qualquer momento (BAUMAN, 1999). Michel Serres (1990) lembra-nos que nossa relação com o mundo mudou completamente, pois adquirimos uma forma diferente de conviver e aprender.

Diante do que Bauman (1999) chama de modernidade líquida, também se amplia a individualidade humana, uma vez que se fragiliza os laços humanos, e em sua vida cotidiana nem sempre a experiência possibilita a conexão significativa entre os acontecimentos, mas acaba se revelando esvaziada de reciprocidade e comunicação do homem. Em razão do vazio de sentido que Raimundo Pelado sente na sua experiência real, ele busca outros espaços de sentido, uma vez que "o saber da experiência se dá na relação entre o conhecimento e a vida humana" (BONDÍA, 2002, p.19).

A questão é que os universos de sentido são complexos, pois envolvem múltiplas visões de mundo. Apresenta-se repleto de informações e comunicações. Rodrigues Garcia (1994) nos ajuda a compreender nossa comunicação com o mundo ao nosso redor, com os outros, e esse "intra" interior conosco mesmo. Ele nos lembra que:

[...] na experiência comunicacional intervêm processos de interlocução e de interação que criam, alimentam e estabelecem os laços sociais e a sociabilidade entre os indivíduos e grupos sociais que partilham os mesmos quadros de experiência e identificam as mesmas ressonâncias históricas de um passado comum. (GARCIA,1994, p. 75)

A complexidade nasce desse jogo de diversas interpretações do existente, ou seja, das diferentes trajetórias biográficas que se encontram em espaços comuns em nosso cotidiano. E é através dessas relações de reciprocidade e sociabilidade que permitem que o mundo constitua um meio de nos unir. A unidade que se refere integra um todo complexo de irregularidades e contradições. De acordo com Araújo e Marques (2018), “a complexidade reconhece a parcela inevitável de desordem e de eventualidade em todas as coisas, ela reconhece a parcela inevitável de incerteza no conhecimento" (2018, p. 40). Logo, os múltiplos saberes e conhecimentos construídos a partir da experiência ao mesmo tempo que cria um espaço que permite a sociabilidade entre os indivíduos, também reconhece as incertezas, a desordem desses encontros, que se constroem e se desconstroem cada vez com mais fluidez.

Desta forma, o espaço interacional se constrói como um campo de disputas que envolve múltiplas possibilidades de comunicação, pode-se optar pela visão única de mundo, que exclui tudo que é diferente, ou, busca-se escutar ativamente todos os pontos de vista, "[...] potencializando nosso modo de estar no mundo e nas relações, em qualquer contexto" (MOURA e GIANNELLA, 2016, p.14). É entre esses dois lugares que o protagonista do conto se encontrava, tendo que optar pelo vazio das relações reais, ou reconstruir o seu lugar de existência em um novo espaço de sentido compartilhado.

Sodré (1988, p. 18), distingue os extremos da existência e da proximidade espacial, para ele as relações espaciais são inapreensíveis e inteligíveis como um princípio de coexistência da diversidade. Constituindo assim uma garantia do exercício de várias possibilidades de comunicação, pois, o intuito de se buscar esse espaço compartilhado é o de criar a solidariedade, laços culturais, e desse modo a identidade. Então, quando se encontra esse lugar, o novo obriga o homem a um novo aprendizado. É a memória olhando para o passado. É a formação de uma consciência que olha para o futuro.

Ramos (1939), enfatiza em sua narrativa $A$ terra dos meninos pelados, esse "ser", esse homem de fora, portando uma memória provinda de um outro lugar, e leva-o a um lugar novo com novos aprendizados. Um espaço paraíso, onde o homem e a natureza se entendem harmonicamente. Raimundo é surpreendido nesse novo espaço com tantas descobertas, que a sua memória do passado desconhecia, e passa a apreender novos conhecimentos. Esse fenômeno para Santos (2010, p. 598) se explica quando:

O homem busca reaprender o que nunca lhe foi ensinado, e
pouco a pouco vai substituindo a sua ignorância do entorno
por um conhecimento[...]. O novo meio ambiente opera
como uma espécie de detonador. Sua relação com o novo
morador se manifesta dialeticamente como territorialidade
nova e cultura nova[...], mudando-se paralelamente
territorialidade e cultura; e mudando o homem.

Dessa forma, o novo espaço encontrado pelo personagem principal do livro, apresenta uma possibilidade de construção de novos mundos possíveis, lugares outros de sociabilidade e reciprocidade que 
ensinam e transformam a partir de novos conhecimentos. Da mesma forma em meio a fluidez e vazio de sentido da experiência do cotidiano, o ser humano tem objetivado construir e reconstruir suas relações de reciprocidade e de comunicação/interação em busca de inclusão e novos sentidos para sua própria existência.

\section{Novos Espaços E Novas Experiências}

Raimundo, personagem principal do texto em estudo, adentrou um novo mundo. Os objetos, a natureza, o espaço físico, eram muito parecidos com o seu lugar anterior, e tinham vida própria. No entanto, a subjetividade dos habitantes daquela terra era bem diferente da conhecida por ele anteriormente. Na cidade de Tatipirun as relações com o outro eram bem mais sociáveis. E ele tinha voz para poder se manifestar quanto as suas opiniões. Quando Graciliano Ramos escreve $A$ terra dos meninos pelados, ele quer transmitir ao leitor a consciência de querer viver o novo, ainda que haja diferenças.

Refletindo sobre um viver sociável em meio as diferenças, o autor Boaventura de Souza Santos, corrobora com Graciliano ramos em sua obra Pela mão de Alice, quando traz uma reflexão sobre a transição entre paradigmas da sociedade, ou seja, os diferentes modos básicos de viver a vida em sociedade. Tratando da habilidade de entrar em diferentes lugares, daqueles com os quais estamos acostumados. O homem em busca de experiências inovadoras, em busca de uma identidade sólida e própria.

Santos (2007) resgata, em sua obra, o mundo de fantasias de Alice no país das maravilhas de Lewis Carroll (1985) para mostrar a necessidade da construção de novos paradigmas. Da mesma forma, Raimundo, em A terra dos meninos pelados, descobria assim sua verdadeira identidade e seu lugar no mundo. Ainda que permanecesse as distinções e as diferenças entre ele e o outro, o resultado final do dialogismo era positivo.

Esse diálogo ocorre dentro de uma interação social, porém, vivemos em uma sociedade com muitos problemas, mas com probabilidades de resolução, a partir da reinvenção da emancipação social, como já citado anteriormente. Santos (2007) reforça a "ideia de que necessitamos de uma sociedade melhor, de que necessitamos de uma sociedade mais justa. As promessas da modernidade - a liberdade, a igualdade e a solidariedade - continuam sendo uma aspiração para a população mundial." (p. 19). As realidades sociais são diferenciadas, e, por isso, as experiências sociais vividas e as expectativas esperadas também, tudo depende do meio em que há essa sociabilidade. Portanto, assim como Raimundo, "A gente vive lutando por coisas novas". (SANTOS, 2007, p. 24)

\section{Considerações Finais - O Renascer De "Raimundo" Para A Humanidade}

A humanidade tem trilhado um caminho cheio de desafios desde os seus primórdios. Com muitos altos e baixos, devido às guerras e a busca pelo poder. Dessa forma, no tempo presente, ela vem sendo submetida a um processo fortemente contraditório de unificação técnica e desagregação social. Os homens nunca se viram, tal como hoje, aproximados uns dos outros pelos instrumentos de informação e comunicação, e, contraditoriamente, nunca estiveram tão solitários como consequência dessa nova era da tecnologia e da computação.

O conjunto de representações que os homens têm a respeito da sociedade, a maneira como pensam e como veem, é o que permite que a mesma permaneça, identificável e reconhecível. É através dessas representações que a sociedade cria homens e mulheres adequados a suas necessidades. É a partir delas que se desenvolvem os processos de introdução dos que nascem nos meandros da sociedade que os recebe. Isso significa que as visões que os homens e as mulheres portam sobre sua sociedade são formas através das quais ela permanece, para cada um individualmente e também para o conjunto humano.

No conto A terra dos meninos pelados de Graciliano Ramos, o renascer de um Raimundo que se liberta das amarguras e tristezas em relação aos olhares dos outros sobre ele. Um novo indivíduo que, a partir desse momento, conseguirá viver com suas diferenças. Dessa forma, ele abandona a condição primeira da repressão de si mesmo, e encontra a fonte da vida, uma condição diferente, madura, de enfrentamento da realidade. Nosso protagonista traz no regresso seu autoconhecimento para aceitar-se como ele é. Superando a crise que o incomodava perante a comunidade que o afrontava.

O texto possibilita uma aproximação com os enfrentamentos cotidianos, e das diferenças que integram o espaço social, no intuito de se refletir novas formas de sociabilidades, mais inclusivas, o que requer uma reforma no pensamento e nos processos de sociabilização.

Para tanto, o desenvolvimento real e mais humano dos seres requer a análise das perspectivas que envolve sua construção social, emanando assim, possibilidades de aprofundamento de pesquisa nos estudos das condutas humanas, sempre a partir de suas subjetividades em situações construídas cotidianamente, através das relações interpessoais e compreendendo os diálogos para a compreensão um do outro 


\section{Notas}

1. Mestre em Letras. Professora do Departamento de Literatura - UFC. Rev. de Letras - N0 40. 25 - Vol. 1/2 - jan/dez. 2003.

2. Para Milton Santos (2008), o espaço geográfico é uma funcionalização da globalização. Uma Globalização, que valorize a singularidade das relações humanas em sua inserção, desembocando em um mundo mais solidário. Afinal quem se globaliza mesmo são as pessoas.

3. A cultura humanista volta-se para as grandes interrogações humanas, visando estimular a reflexão sobre o saber, além de favorecer a integração pessoal dos conhecimentos. Já a cultura científica é vista como de outra natureza, que separa os campos do conhecimento, faz admiráveis descobertas, teorias geniais, entretanto, é privada de reflexão sobre os problemas gerais e globais, não busca uma reflexão sobre as questões humanísticas. (MORIN; LE MOIGNE, 2000).

4. Remetendo o olhar para o nível de realidade integrada, impõe-se colocar a conjunção - "e" para significar a junção desses pares, como razão -e emoção, indivíduo —e sociedade, saúde —e doença, subjetivo —e objetivo (SANTOS, 2008).

5. Segundo Akotirene (2019) a Interseccionalidade é o estudo da sobreposição ou intersecção de identidades sociais e sistemas relacionados de opressão, dominação ou discriminação, nos permitindo enxergar a colisão das estruturas.

\section{Referências}

BAUMAN, Zygmunt. Modernidade Líquida. Rio de Janeiro: Jorge Zahar, 2001

BAKHTIN, Mikhail. Marxismo e filosofia da linguagem. 12 ed. São Paulo: 2006. - Capítulo 1 - Estudo das ideologias e filosofia da linguagem, p 3139

DE ARAÚJO, D.F.M.S; MARQUES, JB. Complexidade e transdisciplinaridade: novos caminhos para o estudo das normas legais. Revista Mosaico. 2018 Jan./Jun.; 09 (1): 35-43

FREIRE, Paulo. Pedagogia da esperança. Rio de Janeiro: Paz e terra, 1992

LACOMBE, Marcelo S. Masset. Os fundamentos marxistas de uma sociologia do cotidiano. Revista-Outubro-Edição-17, 2008, p 145-172.

MARTINS, José de Souza. O senso Comum e a vida cotidiana. Tempo social; Rev. Sociol. USP. S. Paulo, maio de 1998.

MORIN, Edgar. A cabeça bem-feita: repensar a reforma, reformar o pensamento; tradução Eloá Jacobina. - 8a ed. -Rio de Janeiro: Bertrand Brasil, 2003.

; LE MOIGNE, J.L. A inteligência da complexidade. Tradução de Nurimar Maria Falci. São Paulo: Peirópolis, 2000

RAMOS, Graciliano. A terra dos meninos pelados. $41^{\circ}$ edição. Editora Record. São Paulo, 2011.

RODRIGUES, GARCIA, José Luiz. Nuestros Magníficos Pasados, El mundo, 9 abr. 1994

SANTOS, Boaventura de Souza. Epistemologias do Sul. In: MENESES, Maria Paula (org) São Paulo: Cortez, 2010. - Capítulo 17 - O lugar e o cotidiano, p 584-602.

SANTOS, Boaventura de Souza. Pela mão de Alice: o social e o político na pós-modernidade. São Paulo: Cortez, 1995. - Capítulo 6 - Modernidade, identidade e a cultura de fronteira, p 135-157.

SANTOS, Boaventura de Souza. Renovar a teoria crítica e reinventar a emancipação social. São Paulo: Cortez, 2007. - Capítulo 1 - a sociologia das Ausências e a Sociologia das emergências: para uma ecologia de saberes, p 17-49.

SANTOS, Milton. Por uma outra globalização. Rio de Janeiro: Editora Record, 2008 ( $15^{\mathrm{a}}$ edição).
SODRÉ, Muniz. O terreiro e a cidade: a forma social negro-brasileira. Petrópolis: Vozes, 1988. 